\title{
Risk of atrial fibrillation and stroke in rheumatoid arthritis: Danish nationwide cohort study
}

\author{
(c) $(1)$ (8) OPEN ACCESS
}

\author{
Jesper Lindhardsen research fellow ${ }^{1}$, Ole Ahlehoff research fellow ${ }^{1}$, Gunnar Hilmar Gislason \\ research director ${ }^{1}$, Ole Rintek Madsen research director ${ }^{2}$, Jonas Bjerring Olesen research fellow ${ }^{1}$, \\ Jesper Hastrup Svendsen professor ${ }^{34}$, Christian Torp-Pedersen professor ${ }^{1}$, Peter Riis Hansen \\ research director ${ }^{1}$
}

${ }^{1}$ Department of Cardiology, Copenhagen University Hospital Gentofte, 2900 Hellerup, Denmark; ${ }^{2}$ Department of Internal Medicine—Rheumatology Section, Copenhagen University Hospital Gentofte; ${ }^{3}$ Department of Cardiology, Heart Centre, Copenhagen University Hospital Rigshospitalet, 2100 Copenhagen $\varnothing$, Denmark; ${ }^{4}$ Danish National Research Foundation Centre for Cardiac Arrhythmia (DARC), Copenhagen

\begin{abstract}
Objectives To determine if patients with rheumatoid arthritis have increased risk of atrial fibrillation and stroke.

Design Longitudinal nationwide register based cohort study.

Setting Inpatient and outpatient hospital care in Denmark from 1997 to 2009.

Participants Entire Danish population aged over 15 years without rheumatoid arthritis, atrial fibrillation, or stroke before 1997. Participants with rheumatoid arthritis were identified by individual level linkage of diagnoses and rheumatoid arthritis treatment.

Main outcome measures Rates of atrial fibrillation and stroke.

Results Of 4182335 participants included in the cohort, 18247 were identified as having rheumatoid arthritis during follow-up, with a mean age at disease onset of 59.2 years and a median follow-up of 4.8 years. A total of 156484 people, including 774 with rheumatoid arthritis, were diagnosed as having atrial fibrillation (age and sex matched event rates of 8.2 per 1000 person years in rheumatoid arthritis patients and 6.0 per 1000 person years in the general population), with an adjusted incidence rate ratio of 1.41 (95\% confidence interval 1.31 to 1.51 ). In addition, 165 343 people, including 718 with rheumatoid arthritis, had a stroke (7.6 per 1000 person years in rheumatoid arthritis and 5.7 per 1000 person years in the general population), with a resultant rate ratio of 1.32 (1.22 to 1.42). For both atrial fibrillation and stroke, relative risks were increased in all strata based on thirds of sex and age, with higher relative risks in younger patients but higher absolute risk differences in older patients.

Conclusions Rheumatoid arthritis was associated with an increased incidence of atrial fibrillation and stroke. The novel finding of increased risk of atrial fibrillation in rheumatoid arthritis suggests that this arrhythmia is relevant in cardiovascular risk assessment of these patients.
\end{abstract}

\section{Introduction}

Rheumatoid arthritis has been shown to be associated with substantial cardiovascular comorbidity, but most of the available evidence originates from studies on the risk of myocardial infarction and cardiovascular mortality. ${ }^{1-3}$ In contrast to the risk of myocardial infarction related to rheumatoid arthritis, the results from studies on risk of stroke have been inconsistent, which may reflect the diverse causes of stroke, including atherothrombosis, thromboembolism, and haemorrhage, but also differences in study designs and characteristics of rheumatoid arthritis populations examined. ${ }^{2-10}$ Atrial fibrillation is an important and modifiable risk factor for stroke. ${ }^{11}$ To our knowledge, however, studies on the incidence of atrial fibrillation, and its effect on the risk of stroke, in patients with rheumatoid arthritis have not been reported, even though the incidence of atrial fibrillation is known to be increased by several factors that are more prevalent in people with rheumatoid arthritis, such as heart failure, ischaemic heart disease, and smoking. ${ }^{42-14}$ Furthermore, studies have suggested that inflammation plays a role in the development of atrial fibrillation. ${ }^{15}$ In this study, therefore, we examined the risk of atrial fibrillation and stroke associated with rheumatoid arthritis in a Danish nationwide register based cohort study from 1997 to 2009 .

\section{Methods \\ Study cohort and data sources}

Our study cohort consisted of all Danish inhabitants aged over 15 years on 1 January 1997, as identified through the Danish 
civil registration system. In Denmark, all people are issued with a unique and permanent personal identifier at birth, which enabled data from several individual level Danish nationwide registers to be combined. Data on morbidity came from the national patient register, where diagnoses from all hospital admissions (from 1978) and outpatient activities (from 1995) are listed according to the ICD-8 (international classification of diseases, 8th revision) codes until 1994 and ICD-10 thereafter. Here, dates and institutions providing each patient contact are recorded along with one primary and, if appropriate, one or more secondary diagnoses. All prescriptions dispensed from Danish pharmacies have been registered since 1995 in the Danish register of medicinal product statistics, which we used to obtain information on drug treatment at an individual level, including the anatomical therapeutic chemical class, drug strength, quantity, and date of dispensed prescription. Information on income and migration were available through Statistics Denmark. All the registers used have nationwide coverage; as reporting of data is obligatory and linked to financial reimbursements, they are effectively complete. ${ }^{16} 17$

\section{Cohort entry and follow-up}

We followed the cohort from baseline in 1997 until occurrence of a study end point, emigration, or death or 31 December 2009, whichever came first. We excluded people with a diagnosis of rheumatoid arthritis, atrial fibrillation, or stroke before baseline from the study cohort. We monitored cohort participants for the development of rheumatoid arthritis as determined by ICD-10 codes M05-M06 in combination with a dispensed prescription of disease modifying antirheumatic drugs within one year before or after the time of diagnosis (see web appendix for anatomical therapeutic chemical codes used). This method has previously been validated with both sensitivity and specificity of greater than $80 \% .{ }^{18}$ We used the last of either the prescription date or the date of diagnosis as the starting point for the time at risk with rheumatoid arthritis.

\section{End points and potential endpoint predictors}

We detected cases of atrial fibrillation by admissions with the ICD code I48 (ICD-10) and stroke by admissions with I60, I61, I63, and I64 (ICD-10). Both end points have been validated in the Danish patient registry previously. ${ }^{19-22}$

At study baseline on 1 January 1997, we characterised all cohort participants with regard to potential endpoint predictors. On the basis of dispensed prescriptions during 1996, we established baseline cardiovascular drug use, as well as the presence of diabetes by the use of glucose lowering drugs, as previously done. ${ }^{23} \mathrm{We}$ identified hyperthyroid disease by dispensed antithyroid drugs. We defined hypertension as the concurrent use of at least two antihypertensive agents. ${ }^{24}$ We established the presence of heart failure, ischaemic heart disease, heart surgery, valvular disease, cardiomyopathy, and chronic obstructive pulmonary disease by occurrence of respective ICD codes before baseline. Details of anatomical therapeutic chemical and ICD codes used in the above definitions are listed in the web appendix.

To have a non-inflammatory rheumatic disease as a comparator to rheumatoid arthritis and to evaluate the potential influence of surveillance bias, we also identified participants who received a primary diagnosis of osteoarthritis (ICD-10: M15-19, M47). We calculated an index of socioeconomic status from 1 to 5 on the basis of participants' income in the years 1992-6 standardised by age.
For both end points, we did supplementary analyses in which we matched each patient with rheumatoid arthritis with four controls with same sex and year of birth. We then determined the characteristics described above in each set of matched participants at the index date of the patient with rheumatoid arthritis.

\section{Statistical analysis}

To obtain an accurate allocation of exposure time, people who developed rheumatoid arthritis contributed with time at risk in the reference group until the rheumatoid arthritis index date; that is, outcomes before the index date would be allocated to the reference group. We calculated overall as well as sex and age specific absolute incidence rates (IR) of atrial fibrillation and stroke. We calculated sex and age specific attributable risk with rheumatoid arthritis as exposure $\left(\mathrm{IR}_{\text {rheumatoid arthritis }}-\mathrm{IR}_{\text {general }}\right.$ population $\left(\mathrm{IR}_{\text {rheumatoid arthritis }}\right)$. We fitted multivariable Poisson regression models to estimate incidence rates ratios for atrial fibrillation and stroke in patients with rheumatoid arthritis with the general population as reference. We also analysed the risk of atrial fibrillation and stroke including sex, age, calendar year, and socioeconomic index as covariates by proportional hazard regression models (Cox regression), which yielded identical risk estimates to those from Poisson regression. However, we preferred Poisson regression models because detailed analyses using Cox regression were unfeasible owing to the large size of the study dataset. As analyses showed interaction between age and rheumatoid arthritis status in models evaluating stroke risk, and to assess potential effects of difference in sex distribution, we present both overall and age/sex stratified regression models. In addition to the follow-up time, we used age divided into five year intervals (overall model) and calendar year (overall and age stratified models) as time scales. In the matched design study, we estimated risk as hazard ratios from Cox regression analyses with the matched groups considered as individual strata. We tested proportional hazards assumptions and found them to be valid.

We report continuous variables as means with standard deviations and categorical data as frequencies and percentages, unless otherwise indicated. We considered a two tailed $\mathrm{P}$ value less than 0.05 to be significant and provide $95 \%$ confidence intervals. We used SAS version 9.2 for data management and Stata version 11.1 for statistical analysis. The study was conducted and reported in accordance with the Strengthening the Reporting of Observational Studies in Epidemiology (STROBE) recommendations. ${ }^{25}$

\section{Results}

From the total Danish population, 4282752 people were eligible to enter the study cohort. Figure $1 \Downarrow$ shows a flow chart of the study population, and table $1 \Downarrow$ shows baseline characteristics of people who developed rheumatoid arthritis and the general population. A total of 18247 people were identified as having rheumatoid arthritis, with a female predominance of approximately $70 \%$, a mean age at disease onset of 59.2 (SD 14.1) years and a median follow-up of 4.8 (interquartile range 2.3-8.1) years. During follow-up, 165343 people, including 718 with rheumatoid arthritis, had a stroke and 156484 people, including 774 with rheumatoid arthritis, were diagnosed as having atrial fibrillation. This corresponded to incidence rates of both end points that were significantly higher in patients with rheumatoid arthritis than in the general population, regardless of strata based on sex or age (table $2 \Downarrow$ ). Figures $2 \Downarrow$ and $3 \Downarrow$ 
illustrate the relations between age and rates of atrial fibrillation and stroke in more detail.

\section{Atrial fibrillation}

The overall incidence of atrial fibrillation was approximately $40 \%$ higher in rheumatoid arthritis patients than in the general population (age and sex matched event rates of 8.2 and 6.0 per 1000 person years). Women were at slightly higher relative risk than men, and the relative risk of atrial fibrillation was markedly increased in the youngest age groups; the absolute risk attributable to rheumatoid arthritis ranged from $25 \%$ in the oldest to $70 \%$ in the youngest age group.

The change in risk estimates after inclusion of baseline cardiovascular drug use and comorbidity in the analysis was negligible (table $3 \Downarrow$ ). The risk of atrial fibrillation associated with rheumatoid arthritis was somewhat reduced when all cardiovascular drug use and comorbidity was updated during follow-up (incidence rate ratio 1.24, 95\% confidence interval 1.15 to 1.35 ). Interestingly, this effect was primarily driven by inclusion of loop diuretics (incidence rate ratio 1.25, 1.16 to 1.34 , when these were included alone). To assess the influence of surveillance bias as a result of regular outpatient visits for rheumatoid arthritis, we did several sensitivity analyses. Firstly, we excluded cases of atrial fibrillation within the first month of the rheumatoid arthritis index ( 82 events) to reduce the effect of increased surveillance in relation to the diagnosis (consequent incidence rate ratio $1.39,1.30$ to 1.49 ). Secondly, we repeated analyses including only admissions with atrial fibrillation as the primary diagnosis (consequent incidence rate ratio 1.43 , 1.29 to 1.59 ). Thirdly, we excluded users of vitamin K antagonists at baseline and during follow-up to diminish the contribution of patients with unreported prevalent atrial fibrillation (consequent incidence rate ratio $1.43,1.33$ to 1.53 ). Fourthly, we assessed risk of atrial fibrillation in patients with osteoarthritis (incidence rate ratio $1.17,1.08$ to 1.24 ), which was significantly lower compared with patients with rheumatoid arthritis, even though osteoarthritis is likely to lead to increased surveillance. Fifthly, we restricted analysis to follow-up of approximately half a million patients who were diagnosed as having cardiovascular disease as defined in table $1 \Downarrow$ (consequent incidence rate ratio $1.43,1.24$ to 1.65 ).

\section{Stroke}

Age and sex matched stroke rates were 7.6 per 1000 person years in rheumatoid arthritis patients and 5.7 per 1000 person years in the general population, which corresponded to an overall increase in risk of $30 \%$. Similar to the findings with atrial fibrillation, the relative risk was highest in the younger age groups, but with increasing absolute difference in incidence rates with increasing age up to 80 years and above (fig $3 \Downarrow$ ). By further analogy with the atrial fibrillation results, stroke risk varied minimally in our sensitivity analyses and when compared with that in patients with osteoarthritis.

Concerning contribution of atrial fibrillation to stroke risk, we found that updating atrial fibrillation diagnoses during follow-up slightly lowered the risk estimate for rheumatoid arthritis (incidence rate ratio $1.29,1.20$ to 1.39 ), which was consistent with the finding of no significant interaction between atrial fibrillation and rheumatoid arthritis (incidence rate ratio 0.92; $\mathrm{P}=0.49$ ) and the limited follow-up in the group with both rheumatoid arthritis and atrial fibrillation.

\section{Supplemental matched design study}

In general, baseline characteristics showed modestly increased frequencies of cardiovascular drug use and comorbidity in patients with rheumatoid arthritis (table $4 \Downarrow$ ). The results from Cox regression analyses corroborated the findings of the primary analysis (table $5 \Downarrow$ ). Successive inclusion of main groups of covariates only marginally changed the risk estimates for stroke, whereas a small decrease in risk of atrial fibrillation was observed when baseline cardiovascular drug use was included. This decrease was exclusively driven by the inclusion of loop diuretic use.

\section{Discussion}

This study examined the incidence of atrial fibrillation and stroke in a Danish nationwide register based cohort including more than 18000 patients with rheumatoid arthritis who were followed for up to 13 years. The incidence of atrial fibrillation was found to be $40 \%$ higher in rheumatoid arthritis patients than in the general population, and the risk of stroke in rheumatoid arthritis patients was roughly $30 \%$ higher. For both atrial fibrillation and stroke, we saw remarkable threefold increases in the relative risks in patients with rheumatoid arthritis younger than 50, as also indicated by the high proportion of the risk that was attributable to rheumatoid arthritis in young compared with older patients. Nonetheless, the absolute differences in rates of atrial fibrillation and stroke between people with and without rheumatoid arthritis were highest in the oldest patients.

\section{Comparison with other studies}

To our knowledge, the incidence of atrial fibrillation has not previously been examined in a large rheumatoid arthritis population, and only a very limited number of small clinical studies have examined the occurrence of arrhythmias in these patients, with no reports on atrial fibrillation. ${ }^{26-28}$ Although the increased incidence of atrial fibrillation in patients with rheumatoid arthritis is a novel finding that must be tested in other cohorts, several lines of evidence support this result. Firstly, mounting evidence indicates that heart failure is more prevalent in rheumatoid arthritis compared with controls. ${ }^{13}{ }^{14}$ As heart failure is strongly associated with atrial fibrillation (and vice versa), this observation may explain some of the increased risk of atrial fibrillation, as also suggested by the fact that in our study estimates atrial fibrillation risk were primarily affected by time varying confounder adjustment for loop diuretics, which are routinely used for heart failure. Secondly, patients with rheumatoid arthritis show increased arterial stiffness, which is a risk factor for heart failure and atrial fibrillation..$^{29-31}$ Thirdly, recent reports have also suggested use of glucocorticoids and non-steroidal anti-inflammatory drugs as a risk factor for atrial fibrillation; however, although such associations could explain part of the increased risk of atrial fibrillation in rheumatoid arthritis, these studies were cross sectional in their design and subject to confounding by indication (that is, the drugs were prescribed for diseases associated with atrial fibrillation including rheumatoid arthritis and chronic obstructive pulmonary disease) ${ }^{32}{ }^{33}$ Fourthly, inflammation itself has been proposed as playing a role in development of atrial fibrillation, and increased circulating concentrations of inflammatory markers such as $\mathrm{C}$ reactive protein have been associated with atrial fibrillation and lower rates of successful cardioversion. ${ }^{154}{ }^{35}$ Increased $P$ wave dispersion in electrocardiography, which is considered to be a predictor of atrial fibrillation, also occurs more frequently in people with rheumatoid arthritis and seems to be highly correlated with the 
level of systemic inflammation. ${ }^{36}{ }^{37}$ The sum of current evidence therefore clearly suggests that chronic inflammation contributes to the increased risk of atrial fibrillation in patients with rheumatoid arthritis.

In contrast to consistent data indicating an increased risk of myocardial infarction in rheumatoid arthritis, reports on the rheumatoid arthritis related risk of stroke are conflicting. One recent meta-analysis concluded that the risk of myocardial infarction, but not stroke, was significantly increased in patients with rheumatoid arthritis, whereas another found a twofold increased risk of both stroke and myocardial infarction. ${ }^{23}$ The two most recent large cohort studies in this area of research also had contradictory conclusions. ${ }^{6}{ }^{10}$ As their main difference was in the duration of rheumatoid arthritis at cohort entry, which probably also reflected differences in the rheumatoid arthritis treatment strategy (with more aggressive treatment being the mainstay of modern management), the risk of stroke might be more dependent on the duration of rheumatoid arthritis and its treatment than is the case for the risk of myocardial infarction. We were not able to specifically explore this hypothesis in our study, not least because data on duration of symptoms before diagnosis of rheumatoid arthritis were lacking. However, the marked age dependent relative risk of stroke attributable to rheumatoid arthritis may offer another explanation for the inconsistent results in previous studies, as the differences in stroke risk could be caused by variations in age distributions in the rheumatoid arthritis populations studied. ${ }^{2-10}$ To what extent the increased risk of atrial fibrillation contributed to the increased risk of stroke in rheumatoid arthritis patients was not clear owing to a limited follow-up in these cases, but no major effect modification was noted, which indicated that rheumatoid arthritis was a risk factor for stroke beyond the increased risk of atrial fibrillation.

The increased risk of stroke in patients with rheumatoid arthritis is most likely to represent a multifactorial process in which accelerated inflammation driven atherothrombosis, a higher prevalence of classical risk factors, adverse effects of rheumatoid arthritis treatment, and increased risk of atrial fibrillation play important roles. ${ }^{12} 3038{ }^{39}$ At the time of diagnosis, patients with rheumatoid arthritis already have an increased prevalence of carotid plaques compared with controls. ${ }^{40}{ }^{41}$ Also, endothelial dysfunction and increased vascular stiffness, which are predictors of atherosclerotic disease including stroke, are seen in these patients and may improve after anti-inflammatory treatment, although the very same treatment may augment the cardiovascular risk through other pathways (for example, non-steroidal anti-inflammatory drugs, glucocorticoids, and cytotoxic disease modifying antirheumatic drugs). ${ }^{30} 384243$

\section{Clinical implications}

In the recent years, the care of patients with rheumatoid arthritis has been extended to cover the increased comorbidity, especially that due to cardiovascular disease. Newly developed guidelines recommend annual screening for cardiovascular risk factors in patients with rheumatoid arthritis, to counter the reported increased risk of, for example, acute myocardial infarction and stroke. ${ }^{38}$ As no evidence has been available on the risk of atrial fibrillation, the focus has primarily been on standard primary prevention of hard end points by traditional risk score assessment. Overall, our findings corresponded to one new case of atrial fibrillation per 12 rheumatoid arthritis patients followed for 10 years after diagnosis. Given the augmented risk of atrial fibrillation (which is often asymptomatic) and the ample opportunity for diagnosis of arrhythmia at the recommended annual screening appointments, we suggest that the clinical focus should here include screening for atrial fibrillation, not least in light of the relative easiness of such screening, the risk of stroke with subsequent disability and societal burden, and the powerful effect of anticoagulation treatment. Moreover, these findings may indicate that rheumatoid arthritis can add to future risk stratification scores for stroke in patients with atrial fibrillation and lower the threshold for anticoagulation. As inflammation is likely to play a significant role in the pathogenesis of atrial fibrillation and stroke, this study also underlines the importance of rigorous control of inflammation with disease modifying antirheumatic drugs, not only for the management of joint symptoms but also to reduce the need for drugs with potential adverse cardiovascular effects and, ultimately, to diminish the inflammation driven atherothrombotic process.

\section{Strengths and weaknesses}

Although our results were strengthened by a high number of unselected patients with rheumatoid arthritis, an untruncated age span, and a contemporary study cohort, several important limitations should be considered when evaluating the findings. Given the register based approach, people were identified as having rheumatoid arthritis by dispensed prescriptions for disease modifying antirheumatic drugs and recorded diagnoses rather than by use of formal clinical criteria. Therefore, cases of rheumatoid arthritis who were not treated with such drugs as well as cases who did not attend a hospital clinic at any time during the study were excluded. These cases may have a less active disease and hence a lower risk of comorbidity, but they probably represent a small minority of patients, considering the national treatment guidelines in the study period. Conversely, the risk could be underestimated by examining treated patients only, especially as inflammation is likely to be an important contributor to both outcomes. Of note, the incidence of rheumatoid arthritis in this study corresponded closely to those in previous Danish clinic based incidence studies. ${ }^{44}$ The identification of study end points relied on diagnoses from hospital admissions. Whereas stroke usually leads to hospital admission (and thus capture in the registers), this is not always the case for atrial fibrillation. However, the sensitivity of the diagnosis of atrial fibrillation in the national patient register was previously found to be $88 \%$, and the specificity was $88-99 \% .^{19-21}$ Also, the incidence of atrial fibrillation identified in this study was similar to the findings in a large contemporary European population based study. ${ }^{45}$

Surveillance bias due to more frequent examinations in patients with rheumatoid arthritis may have exaggerated the risk of atrial fibrillation related to rheumatoid arthritis and was therefore assessed in several sensitivity analyses. Importantly, when analysis was restricted to cases in which atrial fibrillation was the primary cause of admittance, which are less likely to be differential with regard to rheumatoid arthritis status as such cases are most often due to sudden onset of significant symptoms, the results were not affected. Also, findings were consistent in people with previous cardiovascular disease, among whom both rheumatoid arthritis patients and controls would arguably have similar level of surveillance for the diagnosis of atrial fibrillation. Moreover, until recently, ${ }^{38}$ cardiovascular examinations including pulse assessment and cardiac auscultation were usually restricted to initial evaluation at diagnosis of rheumatoid arthritis, but exclusion of end points within the first month after diagnosis had no effect on our findings.

Another important consideration was whether our adjustments for confounding factors were adequate. In general, we controlled 
for age and calendar year by including these as additional time scales and by presenting age stratified results. In addition, the main results were similar in age and sex matched models in which length of follow-up was similar in the two groups, averaging five years. We lacked information on several important cardiovascular risk factors, and as patients with rheumatoid arthritis may have a higher prevalence of smoking, dyslipidaemia, and reduced physical exercise, availability of such information could change the risk estimates, although some of this unmeasured confounding was probably controlled for by inclusion of several cardiovascular drugs and comorbidities in the analyses

Moreover, most of these confounders, such as heart failure and dyslipidaemia, reduced physical exercise, and adverse effects of antirheumatoid arthritis drugs are inherently prevalent in rheumatoid arthritis and to some extent represent intermediaries in the pathway from rheumatoid arthritis to stroke or atrial fibrillation. Consequently, their inclusion in our analyses would tend to underestimate the risk of atrial fibrillation and stroke in the average patient with rheumatoid arthritis.

Overall, these potential sources of bias and confounding were inherent to the observational nature of our study and, despite our attempts to identify their contributions to the results, we cannot exclude the effects of additional unmeasured factors.

\section{Conclusions}

This study of more than 18000 patients with rheumatoid arthritis found a $40 \%$ increase in risk of atrial fibrillation and a $30 \%$ increase in the risk of stroke. The augmented risk of stroke in rheumatoid arthritis adds significantly to existing evidence, and the novel finding of an increased incidence of atrial fibrillation suggests that this arrhythmia is relevant in cardiovascular risk assessment of these patients.

Contributors: JL made primary contributions to study design, data collection, data analysis, interpretation of results, and writing the manuscript. PRH helped to write the first draft. OA, GHG, CTP, and $\mathrm{PRH}$ contributed to the study design. All authors contributed to the interpretation of results and critical revision of the manuscript and approved the final manuscript. $\mathrm{JL}$ is the guarantor.

Funding: JL has received an unrestricted grant from the Danish Rheumatism Association. The funding source had no influence on the study design, interpretation of results, or decision to submit the article. Competing interests: All authors have completed the Unified Competing Interest form at www.icmje.org/coi_disclosure.pdf (available on request from the corresponding author) and declare: no support from any organisation for the submitted work; no financial relationships with any organisations that might have an interest in the submitted work in the previous three years; no other relationships or activities that could appear to have influenced the submitted work.

Ethical approval: This study was approved by the Danish Data Protection Agency (reference 2008-41-2685). Approval from an ethics committee is not required for administrative register studies in Denmark.

Data sharing: No additional data available.

Meune C, Touzé E, Trinquart L, Allanore $Y$. Trends in cardiovascular mortality in patients with rheumatoid arthritis over 50 years: a systematic review and meta-analysis of cohort with rheumatoid arthritis over 50 years: a systematic
studies. Rheumatology (Oxford) 2009;48:1309-13.

2 Lévy L, Fautrel B, Barnetche T, Schaeverbeke T. Incidence and risk of fatal myocardial infarction and stroke events in rheumatoid arthritis patients: a systematic review of the literature. Clin Exp Rheumatol 2008;26:673-9.

3 Meune C, Touzé E, Trinquart L, Allanore Y. High risk of clinical cardiovascular events in rheumatoid arthritis: levels of associations of myocardial infarction and stroke through a systematic review and meta-analysis. Arch Cardiovasc Dis 2010;103:253-61.

4 Goldstein LB, Bushnell CD, Adams RJ, Appel LJ, Braun LT, Chaturvedi S, et al. Guidelines for the primary prevention of stroke: a guideline for healthcare professionals from the American Heart Association/American Stroke Association. Stroke 2011;42:517-84.
5 Solomon DH, Karlson EW, Rimm EB, Cannuscio CC, Mandl LA, Manson JE, et al. Cardiovascular morbidity and mortality in women diagnosed with rheumatoid arthritis. Circulation 2003;107:1303-7.

6 Solomon DH, Goodson NJ, Katz JN, Weinblatt ME, Avorn J, Setoguchi S, et al. Patterns of cardiovascular risk in rheumatoid arthritis. Ann Rheum Dis 2006;65:1608-12.

7 Sodergren A, Stegmayr B, Ohman ML, Wallberg-Jonsson S. Increased incidence of stroke and impaired prognosis after stroke among patients with seropositive rheumatoid arthritis. Clin Exp Rheumatol 2009;27:641-4.

8 Liang KP, Liang KV, Matteson EL, McClelland RL, Christianson TJ, Turesson C. Incidence of noncardiac vascular disease in rheumatoid arthritis and relationship to extraarticular disease manifestations. Arthritis Rheum 2006;54:642-8.

9 Wolfe F, Freundlich B, Straus WL. Increase in cardiovascular and cerebrovascular disease prevalence in rheumatoid arthritis. $J$ Rheumatol 2003;30:36-40.

10 Holmqvist ME, Klareskog L, Alfredsson L, Askling J. Stroke in rheumatoid arthritis: (when) is there an increased risk? Ann Rheum Dis 2010;69(suppl 3):109.

11 Camm AJ, Kirchhof P, Lip GY, Schotten U, Savelieva I, Ernst S, et al. Guidelines for the management of atrial fibrillation: the Task Force for the Management of Atrial Fibrillation of the European Society of Cardiology (ESC). Eur Heart J 2010;31:2369-429.

12 Boyer JF, Gourraud P-A, Cantagrel A, Davignon J-L, Constantin A. Traditional cardiovascular risk factors in rheumatoid arthritis: a meta-analysis. Joint Bone Spine 2011;78:179-83.

13 Wolfe $F$, Michaud K. Heart failure in rheumatoid arthritis: rates, predictors, and the effect of anti-tumor necrosis factor therapy. Am J Med 2004;116:305-11.

14 Nicola PJ, Crowson CS, Maradit-Kremers H, Ballman KV, Roger VL, Jacobsen SJ, et al. Contribution of congestive heart failure and ischemic heart disease to excess mortality in rheumatoid arthritis. Arthritis Rheum 2006:54:60-7.

15 Engelmann MD, Svendsen JH. Inflammation in the genesis and perpetuation of atrial fibrillation. Eur Heart J 2005;26:2083-92.

16 Gaist D, Sorensen HT, Hallas J. The Danish prescription registries. Dan Med Bull 1997;44:445-8.

17 Andersen TF, Madsen M, Jorgensen J, Mellemkjoer L, Olsen JH. The Danish national hospital register: a valuable source of data for modern health sciences. Dan Med Bull 1999;46:263-8.

18 Singh JA, Holmgren AR, Noorbaloochi S. Accuracy of Veterans Administration databases for a diagnosis of rheumatoid arthritis. Arthritis Rheum 2004;51:952-7.

19 Frost L, Vestergaard P. Alcohol and risk of atrial fibrillation or flutter: a cohort study. Arch Intern Med 2004;164:1993-8.

20 Mukamal KJ, Tolstrup JS, Friberg J, Jensen G, Gronbaek M. Alcohol consumption and risk of atrial fibrillation in men and women: the Copenhagen City Heart Study. Circulation 2005;112:1736-42.

21 Frost L, Andersen LV, Vestergaard P, Husted S, Mortensen LS. Trend in mortality after stroke with atrial fibrillation. Am J Med 2007;120:47-53.

22 Krarup L-H, Boysen G, Janjua H, Prescott E, Truelsen T. Validity of stroke diagnoses in a national register of patients. Neuroepidemiology 2007;28:150-4.

23 Lindhardsen J, Ahlehoff O, Gislason GH, Madsen OR, Olesen JB, Torp-Pedersen C, et al. The risk of myocardial infarction in rheumatoid arthritis and diabetes mellitus: a Danish nationwide cohort study. Ann Rheum Dis 2011;70:929-34.

24 Olesen JB, Lip GY, Hansen ML, Hansen PR, Tolstrup JS, Lindhardsen J, et al. Validation of risk stratification schemes for predicting stroke and thromboembolism in patients with atrial fibrillation: nationwide cohort study. BMJ 2011;342:d124.

25 Von Elm E, Altman DG, Egger M, Pocock SJ, Gotzsche PC, Vandenbroucke JP. Strengthening the Reporting of Observational Studies in Epidemiology (STROBE) statement: guidelines for reporting observational studies. BMJ 2007;335:806-8.

26 Goulenok TM, Meune C, Gossec L, Dougados M, Kahan A, Allanore Y. Usefulness of routine electrocardiography for heart disease screening in patients with spondyloarthropathy or rheumatoid arthritis. Joint Bone Spine 2010;77:146-50.

27 Tłustochowicz W, Piotrowicz R, Cwetsch A, Raczka A, Kramarz E, Nowak J. 24-h ECG monitoring in patients with rheumatoid arthritis. Eur Heart $J$ 1995;16:848-51.

28 Wisłowska M, Sypuła S, Kowalik I. Echocardiographic findings and 24-h electrocardiographic Holter monitoring in patients with nodular and non-nodular rheumatoid arthritis. Rheumatol Int 1999;18:163-9.

29 Mitchell GF, Vasan RS, Keyes MJ, Parise H, Wang TJ, Larson MG, et al. Pulse pressure and risk of new-onset atrial fibrillation. JAMA 2007;297:709-15.

30 Tanasescu C, Jurcut C, Jurcut R, Ginghina C. Vascular disease in rheumatoid arthritis: from subclinical lesions to cardiovascular risk. Eur J Intern Med 2009;20:348-54.

31 Weber T. Systolic and diastolic function as related to arterial stiffness. Artery Res 2010;4:122-7.

32 Christiansen CF, Christensen S, Mehnert F, Cummings SR, Chapurlat RD, Sørensen HT Glucocorticoid use and risk of atrial fibrillation or flutter: a population-based, case-control study. Arch Intern Med 2009;169:1677-83.

33 De Caterina R, Ruigomez A, Rodriguez LA. Long-term use of anti-inflammatory drugs and risk of atrial fibrillation. Arch Intern Med 2010;170:1450-5.

34 Issac TT, Dokainish H, Lakkis NM. Role of inflammation in initiation and perpetuation of atrial fibrillation: a systematic review of the published data. J Am Coll Cardiol 2007;50:2021-8.

35 Liu T, Li G, Li L, Korantzopoulos P. Association between C-reactive protein and recurrence of atrial fibrillation after successful electrical cardioversion: a meta-analysis. $J$ Am Coll Cardiol 2007;49:1642-8

36 Yavuzkir M, Ozturk A, Dagli N, Koca S, Karaca I, Balin M, et al. Effect of ongoing inflammation in rheumatoid arthritis on P-wave dispersion. J Int Med Res 2007;35:796-802.

37 Guler H, Seyfeli E, Sahin G, Duru M, Akgul F, Saglam H, et al. P wave dispersion in patients with rheumatoid arthritis: its relation with clinical and echocardiographic parameters. Rheumatol Int 2007;27:813-8.

38 Peters MJL, Symmons DPM, McCarey D, Dijkmans BAC, Nicola P, Kvien TK, et al. EULAR evidence-based recommendations for cardiovascular risk management in patients with rheumatoid arthritis and other forms of inflammatory arthritis. Ann Rheum Dis 2010;69:325-31.

39 Solomon DH, Kremer J, Curtis JR, Hochberg MC, Reed G, Tsao P, et al. Explaining the cardiovascular risk associated with rheumatoid arthritis: traditional risk factors versus markers of rheumatoid arthritis severity. Ann Rheum Dis 2010;69:1920-5.

40 Hannawi S, Haluska B, Marwick TH, Thomas R. Atherosclerotic disease is increased in recent-onset rheumatoid arthritis: a critical role for inflammation. Arthritis Res Ther 2007;9:R116. 


\section{What is already known on this topic}

Patients with rheumatoid arthritis have increased risk of myocardial infarction and cardiovascular death The incidence of atrial fibrillation in rheumatoid arthritis is unknown

Data on the risk of stroke in rheumatoid arthritis are contradictory, and the role of atrial fibrillation in this context is unknown

\section{What this study adds}

Patients with rheumatoid arthritis had a $40 \%$ higher risk of atrial fibrillation compared with the general population The risk of stroke was increased by $30 \%$ in rheumatoid arthritis compared with the general population

The study suggests that increased focus on atrial fibrillation in the cardiovascular risk assessment of patients with rheumatoid arthritis is warranted

41 Van Sijl AM, Peters MJ, Knol DK, de Vet HC, Gonzalez-Gay MA, Smulders YM, et al. Carotid intima media thickness in rheumatoid arthritis as compared to control subjects: a meta-analysis. Semin Arthritis Rheum 2011;40:389-97.

42 Van Eijk IC, Serne EH, Dijkmans BA, Smulders Y, Nurmohamed M. Microvascular function is preserved in newly diagnosed rheumatoid arthritis and low systemic inflammatory activity. Clin Rheumatol 2011;30:1113-8.

43 Mäki-Petäjä KM, Wilkinson IB. Arterial stiffness and inflammation-a potential target for a drug therapy. Artery Res 2010;4:99-107.

44 Pedersen JK, Svendsen AJ, Horslev-Petersen K. Incidence of rheumatoid arthritis in the southern part of Denmark from 1995 to 2001. Open Rheumatol J 2007:1:18-23.

45 Heeringa J, van Der Kuip DAM, Hofman A, Kors JA, van Herpen G, Stricker BHC, et al. Prevalence, incidence and lifetime risk of atrial fibrillation: the Rotterdam study. Eur Heart J 2006;27:949-53.
Accepted: 13 January 2012

\section{Cite this as: BMJ 2012;344:e1257}

This is an open-access article distributed under the terms of the Creative Commons Attribution Non-commercial License, which permits use, distribution, and reproduction in any medium, provided the original work is properly cited, the use is non commercial and is otherwise in compliance with the license. See: http://creativecommons.org/licenses/by$\mathrm{nc} / 2.0 /$ and http://creativecommons.org/licenses/by-nc/2.0/legalcode. 


\section{Tables}

Table 1| Baseline characteristics. Values are numbers (percentages) unless stated otherwise

\begin{tabular}{lcc} 
Characteristic & General population (n=4 164 088) & Rheumatoid arthritis ( $\mathbf{n}=\mathbf{1 8}$ 247) \\
Female sex & $2121459(50.9)$ & $12726(69.7)$ \\
\hline Mean (SD) age (years): & $45.6(18.4)$ & $52.4(14.9)$ \\
\hline Women & $46.8(19.2)$ & $52.0(15.2)$ \\
\hline Men & $44.3(17.6)$ & $53.2(14.0)$ \\
\hline Comorbidity: & $148893(3.6)$ & $936(5.1)$ \\
\hline Hypertension & $27221(0.7)$ & $101(0.6)$ \\
\hline Heart failure & $109382(2.6)$ & $620(3.4)$ \\
\hline Ischaemic heart disease & $16945(0.4)$ & $136(0.7)$ \\
\hline Hyperthyroid disease & $49666(1.2)$ & $270(1.5)$ \\
\hline Chronic obstructive pulmonary disease & $16363(0.4)$ & $101(0.6)$ \\
\hline Heart surgery & $71288(1.7)$ & $368(2.0)$ \\
\hline Diabetes & $3.00(1.41)$ & $2.77(1.39)$ \\
\hline Mean (SD) socioeconomic index & & $942(5.2)$ \\
\hline Cardiovascular drugs: & $150322(3.6)$ & $174(1.0)$ \\
\hline$\beta$ blocker & $28587(0.7)$ & $740(4.1)$ \\
\hline Cholesterol lowering drug & $119704(2.9)$ & $592(3.2)$ \\
\hline ACEl/ARB & $93711(2.3)$ & $1161(6.4)$ \\
\hline Calcium channel blocker & $176078(4.2)$ & $695(3.8)$ \\
\hline Thiazide diuretic & $130861(3.1)$ & $68(0.4)$ \\
\hline Loop diuretic & $15170(0.4)$ & $98(0.5)$ \\
\hline Spironolactone & $14259(0.3)$ & $794(4.4)$ \\
\hline Vitamin K antagonist & $155122(3.7)$ & \\
\hline Platelet inhibitor & & \\
\hline
\end{tabular}

$\mathrm{ACEI}=$ angiotensin converting enzyme inhibitor; $\mathrm{ARB}=$ angiotensin 2 receptor blocker. 
Table 2| Atrial fibrillation and stroke: numbers of events, time at risk, and risk estimates in general population and patients with rheumatoid arthritis

\begin{tabular}{|c|c|c|c|c|c|c|c|c|}
\hline & \multicolumn{3}{|c|}{ General population } & \multicolumn{3}{|c|}{ Rheumatoid arthritis } & \multirow[b]{2}{*}{$\begin{array}{l}\text { Attributable } \\
\text { risk }^{*}(\%)\end{array}$} & \multirow[b]{2}{*}{$\begin{array}{c}\text { Incidence rate ratio } † \\
(95 \% \mathrm{Cl})\end{array}$} \\
\hline & No & $\begin{array}{c}\text { Time at risk (1000 } \\
\text { py) }\end{array}$ & $\begin{array}{l}\text { Incidence (per } \\
1000 \text { py) }\end{array}$ & No & $\begin{array}{l}\text { Time at risk } \\
(1000 \text { py) }\end{array}$ & $\begin{array}{l}\text { Incidence (per } \\
1000 \text { py) }\end{array}$ & & \\
\hline \multicolumn{9}{|c|}{ Atrial fibrillation } \\
\hline Total & 155710 & 47915 & 3.3 & 774 & 94.5 & 8.2 & & 1.42 (1.32 to 1.52$)$ \\
\hline \multicolumn{9}{|c|}{$\begin{array}{l}\text { Women (age in } \\
\text { years): }\end{array}$} \\
\hline All & 73656 & 24532 & 3.0 & 491 & 67.1 & 7.3 & & $1.48(1.36$ to 1.62$)$ \\
\hline$<50$ & 1915 & 12922 & 0.1 & 8 & 16.8 & 0.5 & 69 & 2.96 (1.48 to 5.93$)$ \\
\hline $50-65$ & 9502 & 6387 & 1.5 & 72 & 24.6 & 2.9 & 49 & 1.86 (1.48 to 2.35$)$ \\
\hline$>65$ & 62239 & 5223 & 11.9 & 411 & 25.8 & 16.0 & 25 & 1.26 (1.15 to 1.39$)$ \\
\hline \multicolumn{9}{|c|}{ Men (age in years): } \\
\hline All & 82054 & 23383 & 3.3 & 283 & 27.4 & 10.3 & & 1.33 (1.19 to 1.50$)$ \\
\hline$<50$ & 6033 & 13362 & 0.5 & 9 & 5.9 & 1.5 & 70 & 3.11 (1.62 to 5.98$)$ \\
\hline $50-65$ & 21064 & 6296 & 3.3 & 65 & 10.7 & 6.1 & 45 & $1.72(1.35$ to 2.19$)$ \\
\hline$>65$ & 54957 & 3725 & 14.7 & 209 & 10.8 & 19.4 & 24 & 1.24 (1.09 to 1.43$)$ \\
\hline \multicolumn{9}{|l|}{ Stroke } \\
\hline Total & 164625 & 47884 & 3.4 & 718 & 94.8 & 7.6 & & 1.33 (1.23 to 1.43$)$ \\
\hline \multicolumn{9}{|c|}{$\begin{array}{l}\text { Women (age in } \\
\text { years): }\end{array}$} \\
\hline All & 81772 & 24500 & 3.3 & 457 & 67.2 & 6.8 & & 1.33 (1.22 to 1.46$)$ \\
\hline$<50$ & 6555 & 12905 & 0.5 & 26 & 16.7 & 1.7 & 67 & 3.11 (2.12 to 4.57$)$ \\
\hline $50-65$ & 14163 & 6362 & 2.2 & 90 & 24.5 & 4.7 & 39 & 1.67 (1.36 to 2.06$)$ \\
\hline$>65$ & 61054 & 5233 & 11.7 & 341 & 26.1 & 15.3 & 11 & $1.14(1.02$ to 1.26$)$ \\
\hline \multicolumn{9}{|c|}{ Men (age in years): } \\
\hline All & 82853 & 23384 & 3.5 & 261 & 27.6 & 9.5 & & $1.34(1.19$ to 1.51$))$ \\
\hline$<50$ & 7605 & 13359 & 0.6 & 12 & 5.9 & 2.0 & 72 & 3.61 (2.05 to 6.36$)$ \\
\hline $50-65$ & 23861 & 6285 & 3.8 & 68 & 10.7 & 6.4 & 40 & 1.70 (1.34 to 2.15$)$ \\
\hline$>65$ & 51387 & 3740 & 13.7 & 181 & 11.0 & 16.4 & 16 & 1.21 (1.05 to 1.40$)$ \\
\hline
\end{tabular}

py=person years.

${ }^{*}$ Rheumatoid arthritis as exposure.

†Adjusted for age, sex, and calendar year (age not included in age stratified model). 
Table 3| Atrial fibrillation and stroke: incidence rate ratio $(95 \% \mathrm{Cl})$ associated with rheumatoid arthritis

Model Atrial fibrillation Stroke

Adjusted for sex, age, and calendar year $\quad 1.43(1.33$ to 1.53$) 1.34$ (1.24 to 1.44$)$

Adjusted for above and socioeconomic status $\quad 1.42(1.33$ to 1.53$) 1.33$ (1.23 to 1.43 )

Adjusted for above and baseline cardiovascular drugs ${ }^{*} 1.41$ (1.31 to 1.51$) 1.32$ (1.22 to 1.42)

Adjusted for above and baseline comorbidity ${ }^{*} \quad 1.41$ (1.31 to 1.51$) 1.32$ (1.22 to 1.42 )

*As listed in table 1 (baseline characteristics). 
Table 4| Supplementary matched design analysis of risk of atrial fibrillation and stroke: baseline characteristics. Values are numbers (percentages) unless stated otherwise

\begin{tabular}{|c|c|c|c|}
\hline Characteristic & General population $(n=72988)$ & Rheumatoid arthritis ( $n=18$ 247) & $P$ value for difference ${ }^{\star}$ \\
\hline Female sex & $50904(69.7)$ & $12726(69.7)$ & NA \\
\hline \multicolumn{4}{|l|}{ Mean (SD) age (years): } \\
\hline Women & $58.9(14.8)$ & $58.9(14.8)$ & NA \\
\hline Men & $60.1(13.6)$ & $60.1(13.6)$ & NA \\
\hline \multicolumn{4}{|l|}{ Comorbidity: } \\
\hline Hypertension & $8217(11.3)$ & $2272(12.5)$ & $<0.01$ \\
\hline Heart failure & $952(1.3)$ & $436(2.4)$ & $<0.01$ \\
\hline Ischaemic heart disease & $4139(5.7)$ & $1399(7.7)$ & $<0.01$ \\
\hline Hyperthyroid disease & $1150(1.6)$ & $388(2.1)$ & $<0.01$ \\
\hline Chronic obstructive pulmonary disease & $2131(2.9)$ & $848(4.6)$ & $<0.01$ \\
\hline Heart surgery & $1322(1.8)$ & $439(2.4)$ & $<0.01$ \\
\hline Diabetes & $3174(4.3)$ & $967(5.3)$ & $<0.01$ \\
\hline Mean (SD) socioeconomic index & $3.02(1.41)$ & $2.98(1.41)$ & $<0.01$ \\
\hline \multicolumn{4}{|l|}{ Cardiovascular drugs: } \\
\hline$\beta$ blocker & $6657(9.1)$ & $1895(10.4)$ & $<0.01$ \\
\hline Cholesterol lowering drug & $5955(8.2)$ & $1544(8.5)$ & 0.16 \\
\hline ACEI/ARB & $9029(12.4)$ & $2581(14.1)$ & $<0.01$ \\
\hline Calcium channel blocker & $4764(6.5)$ & $1404(7.7)$ & $<0.01$ \\
\hline Thiazide diuretic & $7982(10.9)$ & $2595(14.2)$ & $<0.01$ \\
\hline Loop diuretic & $3801(5.2)$ & $1843(10.1)$ & $<0.01$ \\
\hline Spironolactone & $745(1.0)$ & $344(1.9)$ & $<0.01$ \\
\hline Vitamin $\mathrm{K}$ antagonist & $697(1.0)$ & $444(2.4)$ & $<0.01$ \\
\hline Platelet inhibitor & $6013(8.2)$ & $1864(10.2)$ & $<0.01$ \\
\hline
\end{tabular}

$\mathrm{ACEl}=$ angiotensin converting enzyme inhibitor; $\mathrm{ARB}=$ angiotensin 2 receptor blocker; $\mathrm{NA}=$ not applicable.

*Unadjusted conditional (matched set) logistic regression. 
Table 5| Supplementary matched design analysis of risk of atrial fibrillation and stroke: hazard ratio (95\% Cl) associated with rheumatoid arthritis

Model Atrial fibrillation Stroke

Adjusted for calendar year (sex and age matched)

1.48 (1.36 to 1.62$) 1.41$ (1.28 to 1.55$)$

Adjusted for above and socioeconomic status $\quad 1.47$ (1.35 to 1.61$) 1.40$ (1.28 to 1.54$)$

Adjusted for above and baseline cardiovascular drugs* 1.40 (1.28 to 1.54$) 1.39$ (1.26 to 1.54)

Adjusted for above and baseline morbidity* 1.39 (1.27 to 1.53$) 1.38$ (1.26 to 1.52$)$

${ }^{*}$ As listed in table 4 (baseline characteristics). 


\section{Figures}

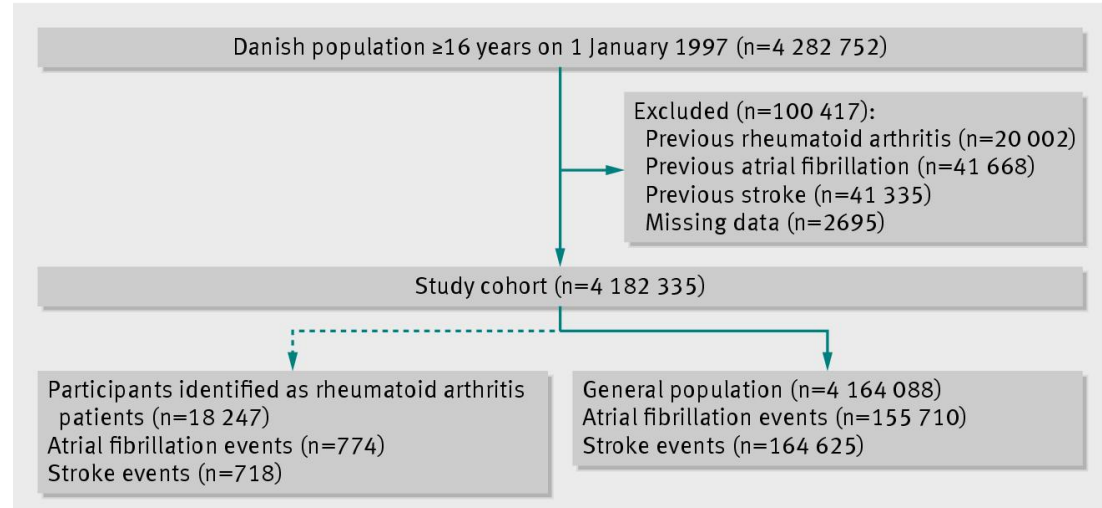

Fig 1 Flow chart of study population

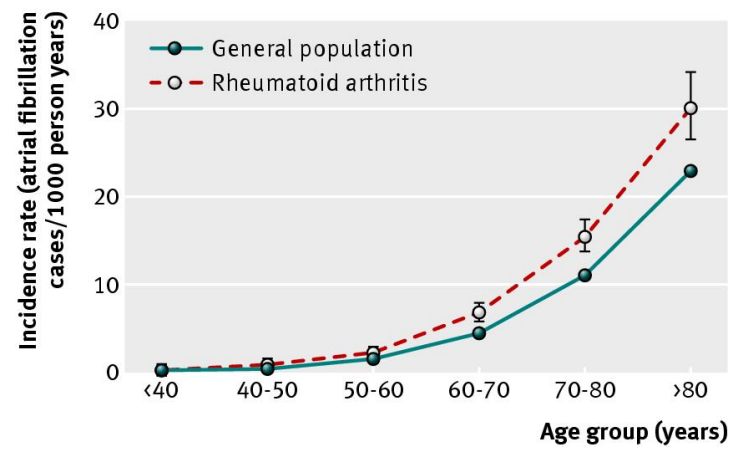

Fig 2 Rates of atrial fibrillation in general population and patients with rheumatoid arthritis

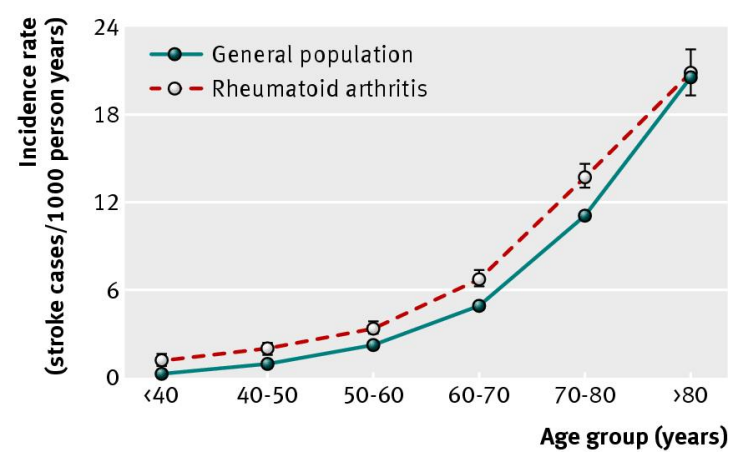

Fig 3 Rates of stroke in general population and patients with rheumatoid arthritis 